\title{
Development and Preclinical Studies of Onthotopic Bone Implants Based on a Hybrid Construction trom Poly(3-Hydroxybutyrate) and Sodium Alginate
}

DOI: $10.17691 / \mathrm{stm} 2016.8 .4 .06$

Received February 18, 2016

A.A. Muraev, MD, PhD, Associate Professor, Department of Maxillofacial Surgery and Implantology,

Faculty of Doctors' Advanced Training'; Associate Professor, Department of Maxillofacial and Oral Surgery²;

A.P. Bonartsev, PhD, Leading Researcher, Department of Bioengineering ${ }^{3}$; Researcher,

Laboratory of Microorganism Nitrogen Fixation;;

Yu.V. Gazhva, MD, PhD, Tutor, Department of Maxillofacial Surgery and Implantology,

Faculty of Doctors Advanced Training';

V.M. Riabova, MD, PhD, Tutor, Department of Maxillofacial Surgery and Implantology,

Faculty of Doctors' Advanced Training';

A.V. Volkov, MD, PhD, Forensic Pathologist ${ }^{5}$;

I.I. Zharkova, Junior Researcher, Department of Bioengineering;

I.A. Stamboliev, PhD Student, Department of Maxillofacial and Oral Surgery2;

E.S. Kuznetsova, Master's Degree Student3;

V.A. Zhuikov, Senior Laboratory Technician, Institute of Biomedical Technologies ${ }^{1}$; PhD Student4;

V.L. Myshkina, PhD, Researcher, Laboratory of Microorganism Nitrogen Fixation";

T.K. Mahina, Researcher, Laboratory of Microorganism Nitrogen Fixation;

G.A. Bonartseva, PhD, Senior Researcher, Laboratory of Microorganism Nitrogen Fixation;;

S.G. Yakovlev, Senior Laboratory Technician, Institute of Biomedical Technologies";

K.S. Kudryashova, Senior Laboratory Technician, Institute of Biomedical Technologies';

Leading Engineer, Department of Bioengineering;

V.V. Voinova, Junior Researcher, Department of Biochemistry3;

A.A. Mironov, PhD, Associate Professor, Department of Neurotechnology, Institute of Biology and Biomedicine

Senior Researcher, Experimental Modeling Unit, Central Research Laboratory; Associate Professor,

Department of Normal Physiology named after N.Y. Belenkov';

K.V. Shaitan, DSc, Professor, Deputy Head of the Department of Bioengineering;";

S.I. Gazhva, MD, DSc, Head of the Department of Dentistry, Faculty of Doctors' Advanced Training';

S.Yu. Ivanov, MD, DSc, Professor, Head of the Department of Maxillofacial Surgery and Implantology,

Faculty of Doctors' Advanced Training'; Head of the Department of Maxillofacial and Oral Surgery ${ }^{2}$

${ }^{1}$ Nizhny Novgorod State Medical Academy, 10/1 Minin and Pozharsky Square, Nizhny Novgorod, 603005,

Russian Federation;

2Peoples' Friendship University of Russia, 6 Miklukho-Maklay St., Moscow, 117198, Russian Federation;

${ }^{3}$ Lomonosov Moscow State University, 1/12 Leninskie Gory, Moscow, 119991, Russian Federation;

${ }^{4}$ Bach Institute of Biochemistry, Federal Research Centre "Fundamentals of Biotechnology" Russian Academy of Sciences, Build. 2, 33 Leninskiy Prospekt, Moscow, 119071, Russian Federation;

${ }^{5}$ City Clinical Hospital named after Ye.O. Mukhin, 17 Federativny Prospekt, Moscow, 111399, Russian Federation;

${ }^{6}$ Lobachevsky State University of Nizhni Novgorod, 23 Prospekt Gagarina, Nizhny Novgorod, 603950,

Russian Federation

The aim of the investigation was to develop a technology of manufacturing bone implants based on a hybrid polymer construction composed of poly(3-hydroxybutyrate) and sodium alginate for guided bone regeneration using 3D printing method.

Materials and Methods. Complex shaped bone implants based on poly(3-hydroxybutyrate) and sodium alginate were manufactured by the method of two-stage leaching using a mold obtained by 3D printing. The appearance, morphology and structure of the obtained scaffolds were analyzed by means of scanning electron microscopy. Biocompatibility in vivo was determined based on the histology data of scaffolds implantation as bone substitutes.

Results. The study of the developed hybrid 3D scaffolds from poly(3-hydroxybutyrate) and sodium alginate showed that they perform a restrictive function providing conditions for regeneration of flat cranial bones in rats.

Conclusion. The developed hybrid 3D scaffolds do not interfere with normal osteogenesis and provide beneficial conditions for regeneration.

Key words: bone implants; polyhydroxyalkanoates; poly(3-hydroxybutyrate); sodium alginate; bone tissue regeneration; biocompatibility.

For contacts: Anton P. Bonartsev, e-mail: ant_bonar@mail.ru 
Reconstruction of complex shaped bone defects is a procedure still remaining complicated in performance. Congenital and, particularly, post-traumatic maxillofacial defects and deformities are notable for a variety of shapes and to replace them not only osteoplastic materials but bone implants $(\mathrm{BI})$ representing the shape of the reconstructed defect are needed [1]. The use of state-ofthe-art software combining the possibility of processing computed tomography data and virtual three-dimensional (3D) modelling enables researchers and clinicians to carry out computer-aided planning in reconstructive surgery and produce models of bone implants completely congruent to the recipient site [2, 3], i.e. the process of preparing $\mathrm{BI}$ model for fabrication can be considered a feasible task.

There are several technologies suggested for manufacturing $\mathrm{Bl}$ of optional geometry. Among them there is milling an allograft bone $[4,5]$, ceramic blocks [6], composite bone scaffolds [7]. However, many researchers report an allograft bone to have a number of drawbacks, while ceramics is characterized with a long resorption period [8]. Another promising technology for $\mathrm{BI}$ fabrication is additive manufacturing, or $3 \mathrm{D}$ printing. Oxford Performance Materials, Inc. was one of the first companies to produce individual extramedullary implants using 3D prototyping technique [9]. In Russia there is a certified and approved for clinical application technology of manufacturing individual extramedullary polytetrafluorethylene implants for contour plastic surgery, however, this category of material is regarded as bioinert, but not biodegradable and not replaced by bone tissue $[3,10]$.

Development of direct 3D printing $\mathrm{BI}$ is complicated by the fact that materials traditionally employed to replace bone defects, polymers (polyhydroxyalkanoates (PHA), polylactides, polyglycolide, etc.), mineral materials (polyhydroxyapatite, calcium salts), xeno- and allomaterials, either do not suit for traditional 3D printing or change their physicochemical and biological properties and become unsuitable for bone reconstruction.

The choice of materials for manufacturing products with preselected shape using indirect 3D technologies is also of great importance. Such materials should provide preselected product microstructure, its physicalchemical and biological parameters (sufficient solidity, plasticity, hydrophilic properties, biodegradability and biocompatibility). However, not always does one material assure the combination of all these properties, therefore, the technologies of manufacturing hybrid constructions using different biopolymers and mineral substances have been actively developing in recent years.

The most frequently used polymers for bioengineering of hard connective tissue are PHA and alginates [11-13]. These polymers are very different in their properties. PHA are hydrophobic, mechanically strong, slowly biodegradable polyesters, while alginates are hydrophilic, hydrogel-forming, mechanically destructible polysaccharides. Generating composites from polymers of these two classes makes it possible to adjust the properties of the resulting composite material very widely. Alginates are frequently used for manufacturing scaffolds in bone, cartilage, soft connective and muscular tissue engineering [12], while PHA-based scaffolds are mostly employed for bone tissue regeneration [11]. PHA, particularly homopolymer poly(3-hydroxybutyrate) (PHB), is generated by biotechnology using highly effective producer strain Azotobacter chroococcum 7B, which gives the opportunity to acquire high purity polymers with preselected properties [14]. Despite the fact that alginates for biomedical purposes are derived from brown algae, these polymers can also be obtained by biotechnology using producer strains of the same bacteria type, Azotobacter chroococcum [15].

The authors have developed a method of manufacturing complex shaped $\mathrm{BI}$ based on PHB and sodium alginate by the method of two-stage leaching using a 3D printed mold.

The aim of the investigation was to develop a technology of manufacturing bone implants based on a hybrid polymer construction made of poly(3hydroxybutyrate) and sodium alginate for guided bone regeneration using $3 \mathrm{D}$ printing method.

\section{Materials and Methods}

Reagents. The following reagents were used: PHB (molecular weight $150 \mathrm{kDa}$ ) and sodium alginate (SigmaAldrich, Germany); trichloromethane (EKOS-1, Russia); ammonium carbonate (Chimmed, Russia); sucrose (Chimmed, Russia); polylactide strand for 3D printing by fused deposition modeling (fusion temperature $200-255^{\circ} \mathrm{C}$, density $1.2-1.08 \mathrm{~kg} / \mathrm{m}^{2}$, environmentally pure, non-toxic, high-accuracy printing, produced by a Moscow factory, FDPlast, Russia); Zoletil 100 (Virbac, France); Rometar (Bioveta, Czech Republic); Doxycycline (Bioenergy, Russia); Tetracycline (Biochemic, Russia); alizarine red (ChimMedService, Russia).

Computer modeling and $3 D$ printing of molds for manufacturing $\mathrm{BI}$. Cone beam computed tomography of the rat's head was performed. 3D model of the skull was reformed based on DICOM files (Figure 1).

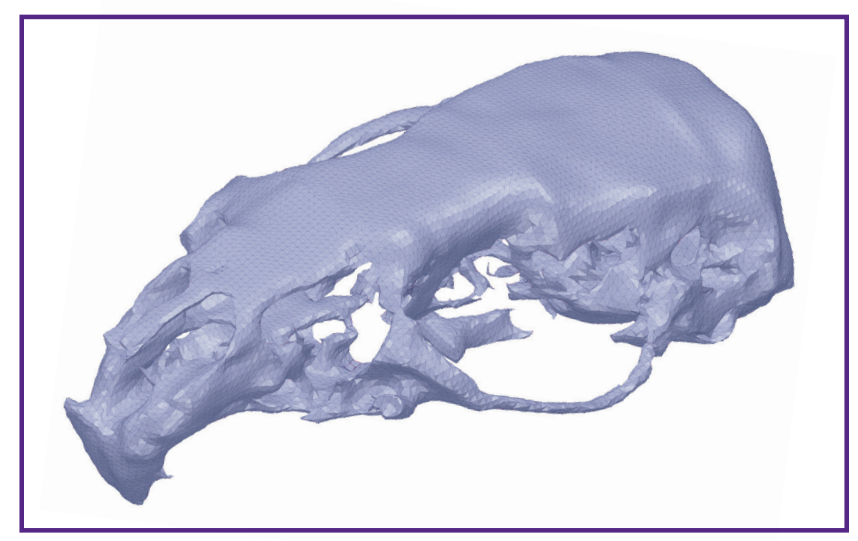

Figure 1. A $3 D$ model of the rat's cranium reformed from DICOM files 
Cylindrically shaped bone defect $8 \mathrm{~mm}$ in diameter was simulated on the center of the parietal bone (Figure 2). The implant model was manufactured so that it not only filled the bone defect, but overlapped it on the outside. This allows protecting the dura mater and the brain from external effects (Figure 3). Since the study was performed

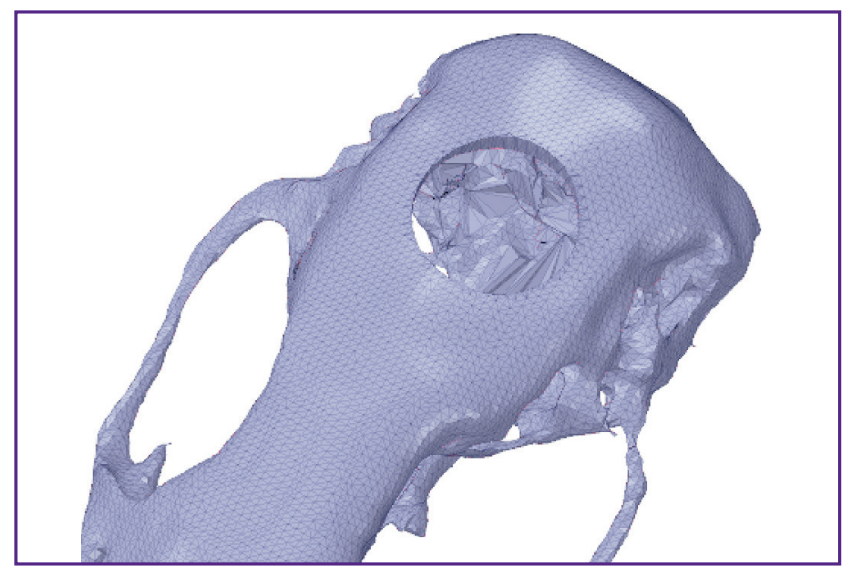

Figure 2. A model of the rat's cranium with a simulated defect

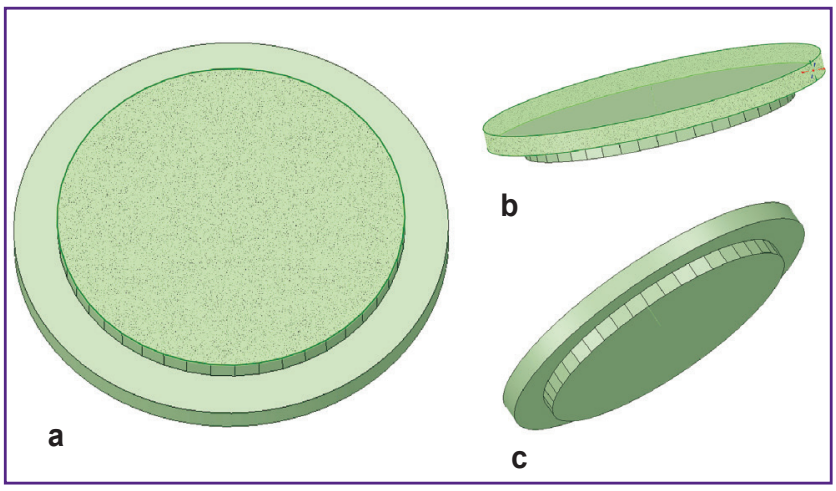

Figure 3. A 3D model of a bone implant: (a) bottom view; (b) side and top view; (c) side and bottom view. The upper part of the implant overlays the bone defect protecting the brain

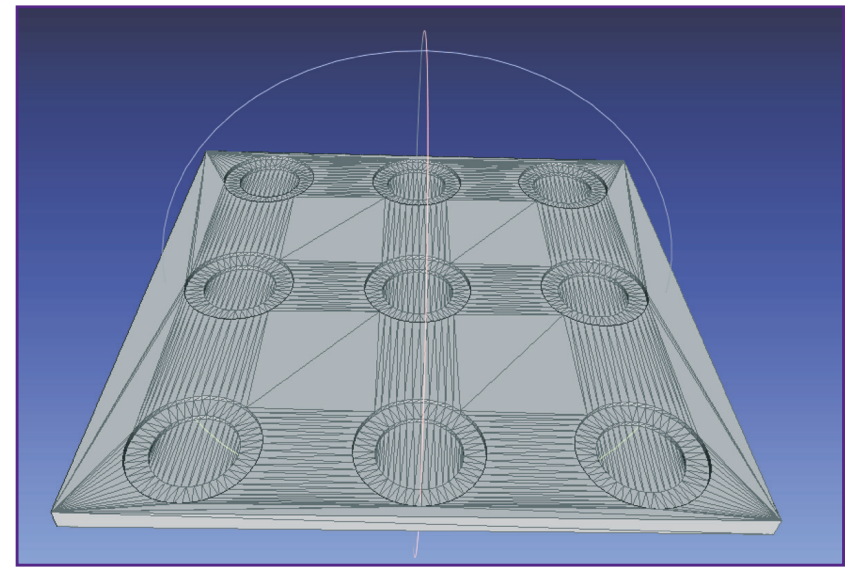

Figure 4. A 3D model of a template for molding implants on rats of equal weight and size, all models were also manufactured in the same size. Figure 4 shows a 3D model of a mold for manufacturing BI.

Manufacturing bone implants with the use of $3 D$ printed molds. The $\mathrm{BI}$ molds were manufactured from polylactide using 3D printer PrusaMendel v2 (NWRepRap, USA) working on the principle of fused deposition modeling. The molds were isolated with aluminum foil as organic solvent chloroform dissolving polylactide was used in the process of manufacturing BI (Figure 5).

Such process of implant molding is easily scaled for manufacturing implants no less than $5 \times 5 \times 5 \mathrm{~cm}$ in size.

Obtaining polymer matrices for manufacturing bone implants. To manufacture porous scaffolds we applied the method of two-stage leaching, which is a new modification of leaching, a method widely used for manufacturing scaffolds in tissue engineering [16]. Ammonium carbonate and sucrose were chosen as pore-forming agents. Ammonium carbonate crystal size amounted to 40-94 $\mu \mathrm{m}$, it was 94-315 $\mu \mathrm{m}$ for sucrose. Size regulation was performed using laboratory sieves U1-ESL with the mesh size 40, 94 and $315 \mu \mathrm{m}$ (Kraft, Russia).

Thermal decomposition of ammonium carbonate occurred on the first stage of double leaching:

$$
\left(\mathrm{NH}_{4}\right)_{2} \mathrm{CO}_{3} \rightarrow 2 \mathrm{NH}_{3}+\mathrm{CO}_{2}+\mathrm{H}_{2} \mathrm{O} \text {. }
$$

In this process pores of a smaller diameter were formed. On the second stage water was changed several times up to the complete washing-out of sucrose.

PHB solution (65 $\mathrm{mg}$ per $1 \mathrm{ml}$ of trichloromethane) was added to the mixture of ammonium carbonate and sucrose (1:3) until the mixture condition was close to that of liquid paste. The mold manufactured earlier was filled with the mixture. After solvent evaporation the mold was submerged in hot water $\left(\sim 90^{\circ} \mathrm{C}\right)$. After gas formation stopped the obtained scaffolds were removed from the mold and washed with distilled water 5 times during 30 min with a shaker.

Before implantation the scaffolds were filled with $1 \%$ alginate solution until full saturation, then they were placed in $50 \mathrm{mM}$ solution of $\mathrm{CaCl}_{2}$ until the complete gelling of alginate in the scaffold, after which the obtained hybrid scaffolds were washed with phosphate buffered saline.

Such hybrid scaffold construction based on PHB filled with sodium alginate was developed with account of previously obtained data $[17,18]$. We have established that barrier membrane of $\mathrm{PHB}$ and the paste for filling bone defects based on microspheres of PHB in alginate gel are effective for bone tissue regeneration. Besides, sodium alginate can be further employed for encapsulating and introduction of mesenchymal stem cells and other cells used for stimulating bone and cartilage tissue regeneration in the scaffold [19].

Matrix structure and morphology. Analysis of appearance, structure and morphology of the obtained scaffolds was performed using scanning electron microscope JSM-6380LA (Tokyo Boeki Ltd., Japan). 

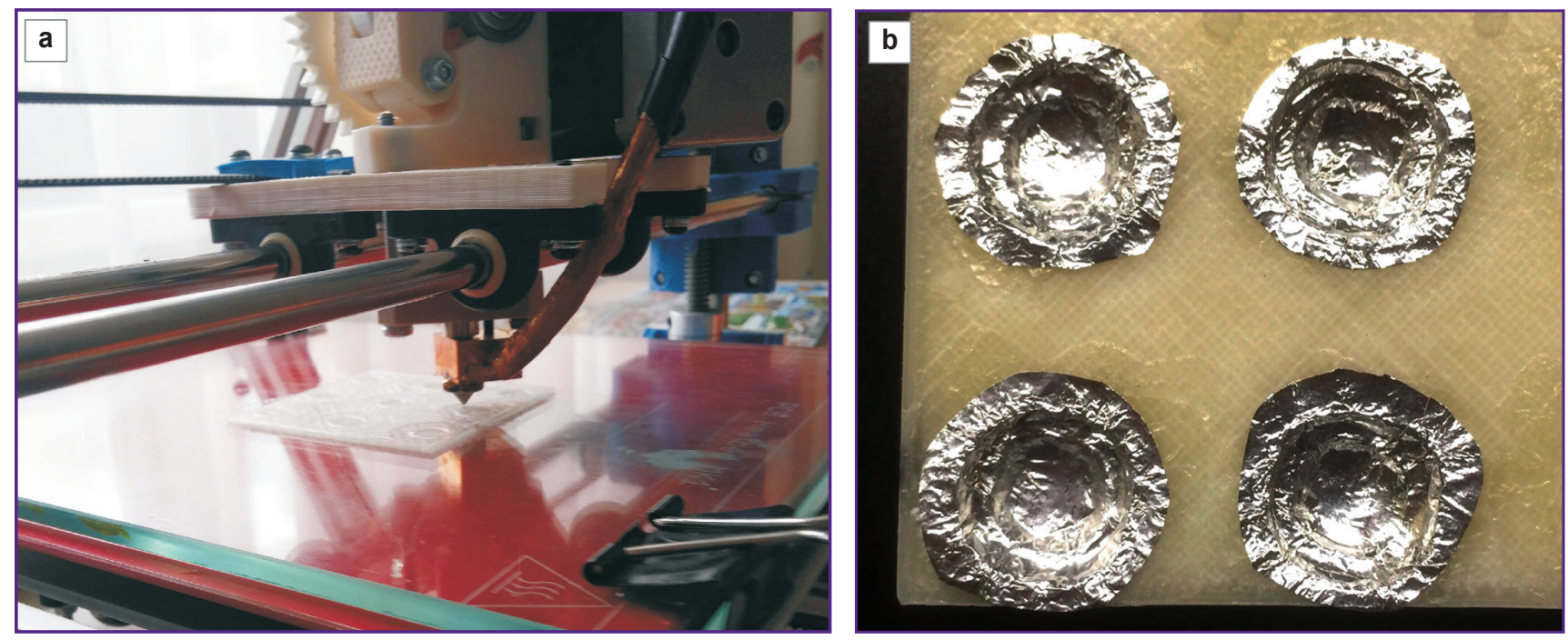

Figure 5. A template for molding implants: (a) at the stage of printing; (b) at the stage of foil insulation

For this purpose the samples were fixed on aluminium tables and sprayed with gold during $15 \mathrm{~min}$ at $15 \mathrm{~mA}$ of amperage (IB-3; Giko Engineering Co., Japan).

Porosity. Matrix porosity was evaluated by weightmeasuring method for testing porosity. First, the porous scaffold weight, diameter and height were measured (Acculab AL-64, USA), the theoretical volume of monolithic scaffold was calculated, the weight of uniform non-porous sample was determined with account of polymer density $\left(1.25 \mathrm{~g} / \mathrm{cm}^{3}\right)$. Porosity $(P)$ was calculated using the formula:

$$
P=\left(1-m_{1} / m_{2}\right) \cdot 100 \%,
$$

where $m_{1}$ is the measured weight of porous sample, and $\mathrm{m}_{2}$ is the calculated weight of monolithic sample without pores, whose volume equals the volume of the porous sample.

The presence of open pores was found by dyeing with ink. The scaffold sample was dipped in ink, dried, and then cut.

In vivo study on a critical bone defect. In studying regeneration of cranial bones the model of critical skullcap defect (parietal bone) in rats is the most revealing [20] as it allows obtaining reproducible data and comparing them with numerous results of other investigations [8, 16-18]. Such model is used to evaluate efficacy and security of various bone-replacing materials, including scaffolds with growth factors and cells [21-23].

Operation technique. The study was carried out on 24 male Wistar rats weighing $400 \mathrm{~g}$. The experiment complied with the recommendations of the Bioethics Committee of Nizhny Novgorod State Medical Academy and was carried out in accordance with "The rules of conducting works using experimental animals" approved by Orders of the Ministry of Health of the USSR No.755 of 12.08.1977, No.701 of 24.07.1978, and "The rules of good laboratory practice in the Russian Federation" dated 19.06.2003.

The rats were anesthetized intra-abdominally with Zoletil 100, $125 \mu \mathrm{g} / \mathrm{kg}$ of body weight. Transverse and laterally displaced vertical incisions were made on the rat's scalp to form a triangular graft, the parietal bones were subsequently exposed by blunt and sharp dissection. A round opening was formed in the middle of the sagittal suture on the parietal bones with a trephine C-reamer $8 \mathrm{~mm}$ in diameter and $1.5 \mathrm{~mm}$ in height from Neobiotech SLA kit (Neobiotech, Korea), avoiding the perforation of sagittal venous sinus. The wound was sutured in layers (Figure 6).

Introduction of fluorescent marks to study bone defect regeneration rate. The mechanism of marking bone regenerate is based on bonding tetracyclinelike fluorochromes with calcium ions forming chelate compounds that accumulate in the neoformed bone tissue, which provides their subsequent visualization. To estimate the dynamics of neo-osteogenesis on different stages intravital threefold marking of the neoformed bone tissue was carried out. All experimental rats were administered intra-abdominal injections of doxycycline solution by the beginning of active osteoid mineralization on day 8,9 and 10 after the operation. Further, on day 15,16 and 17 of the experiment the rats were introduced tetracycline solution intra-abdominally, which generated new marked area penetrating into the neoformed bone tissue. On day 22, 23 and 24 alizarine red $C$ was introduced for complete dyeing the edges of the mineralized regenerate. The marks were introduced in the dose of $25 \mathrm{mg} / \mathrm{kg}$ of body weight. Thus, marking was performed according to the scheme 7-3-4-3-4-3-4 (three days of introduction alternated with four-day breaks).

On day 28, which corresponded to the completion of primary osteogenesis processes [24], the rats were 

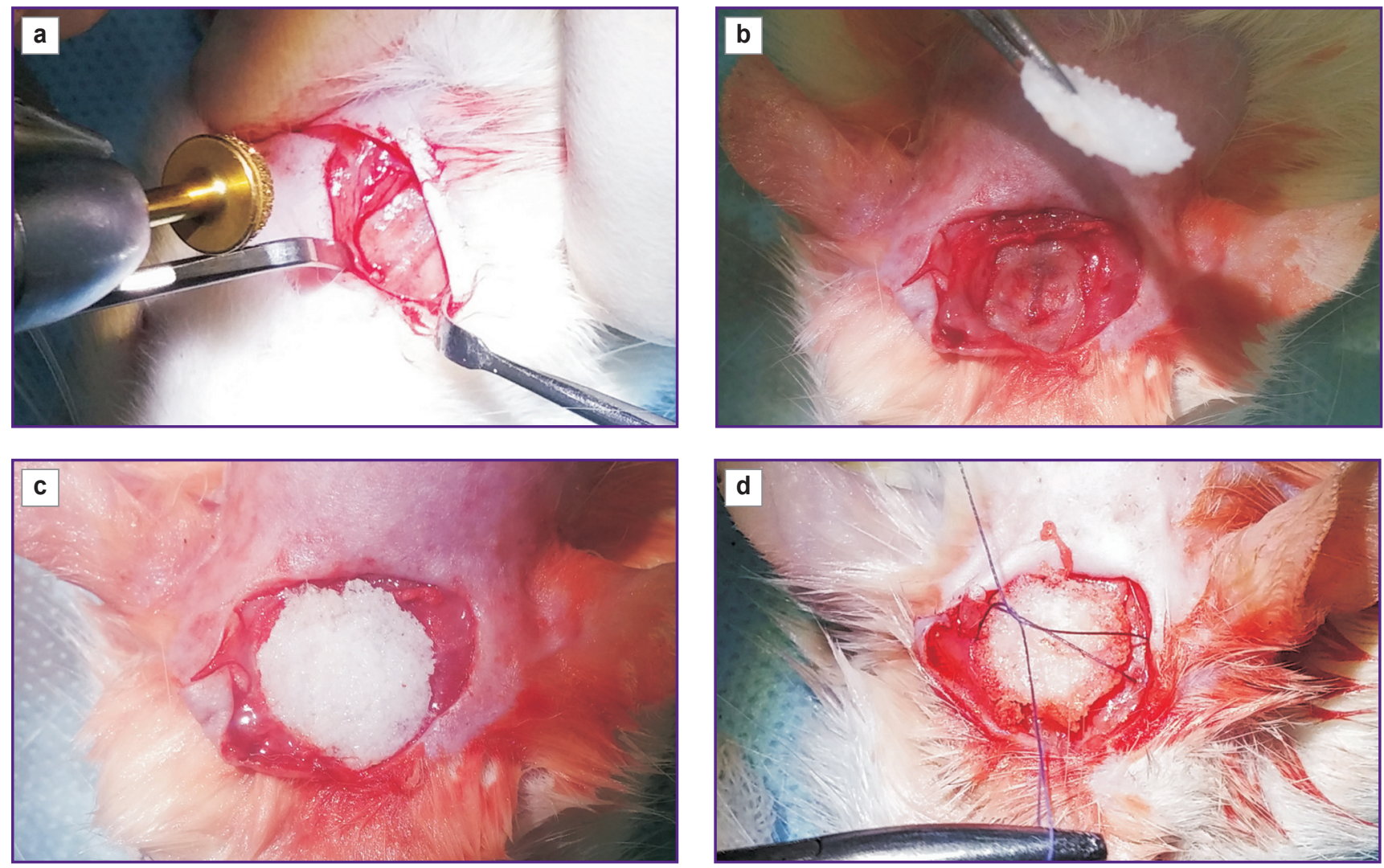

Figure 6. Operation stages: (a) surgical access; (b) formation of a critical bone defect; (c) covering the defect with bone scaffolds; (d) suturing the bone scaffolds to the periosteum

sacrificed with an overdose of Zoletil/Rometar. The calvarium was skeletonized, the regenerate area was harvested using surgical cylindrical drills and console. The obtained calvarium samples were fixed in $40 \%$ ethyl alcohol during $24 \mathrm{~h}$. Such method of fixation is widely used to retain fluorescent marking and good saturation of bone tissue [25].

Histological investigation. The samples were fixed in $70 \%$ ethanol during $24-72 \mathrm{~h}$. After that, they were washed, dehydrated and submerged in methylmethacrylate (Osteo-Bead; Sigma-Aldrich, USA) with subsequent polymerization, according to standard procedure recommended by the manufacturer. The obtained blocks were used to manufacture primary slices of $200 \mu \mathrm{m}$ in thickness (Low Speed Saw, Switzerland), which served for making secondary slices of 40-50 $\mu \mathrm{m}$ in thickness. Slice thickness control was carried out using standard mechanical drum-type micrometer.

Microscopic examination was carried out using fluorescent imaging microscope Leica DM 4000B (Leica Microsystems, Germany). Microphotography was performed using a standard set of optical filters with subsequent combining RGB-channels in a single image by means of standard Leica software product for fluorescence microscopy (multi-channel histopantomogram).

\section{Results and Discussion}

Scaffold structure and morphology. Using the method of two-stage leaching we obtained 3D PHB scaffolds (molecular weight $150 \mathrm{kDa}$ ) (Figure 7). Examination of polymer scaffold samples by scanning electron microscopy (Figure 8) showed that the scaffolds have 3D porous structure with various pore sizes: micropores of $23 \pm 8 \mu \mathrm{m}$, macropores of $410 \pm 75 \mu \mathrm{m}$. Macropores of more than $300 \mu \mathrm{m}$ are considered to be an optimal size for permeating nutrients and cells in all parts of the material [26].

The character of pore system was analyzed by dyeing with ink. The PHB scaffolds were found to have interconnected pore system. On average, scaffold porosity amounted to $93 \%$.

Histological investigation. Microscopic examination of rat's parietal bone tissue samples using fluorescence microscopy revealed that fluorescent marking accumulation in the bone tissue occurred successfully. However, microscopy revealed no distinct color gradient on histological sections as bone tissue volume was accumulating gradually and dyed areas were overlapping. Channel-by-channel examination of light emission by fluorochromes revealed their presence and accumulation in their spectrum, though superposition of images in a single one provided no clear identification of fluorochrome 
Figure 7. The appearance of scaffolds based on poly(3-hydroxybutyrate): (a) before and (b) after saturation with sodium alginate
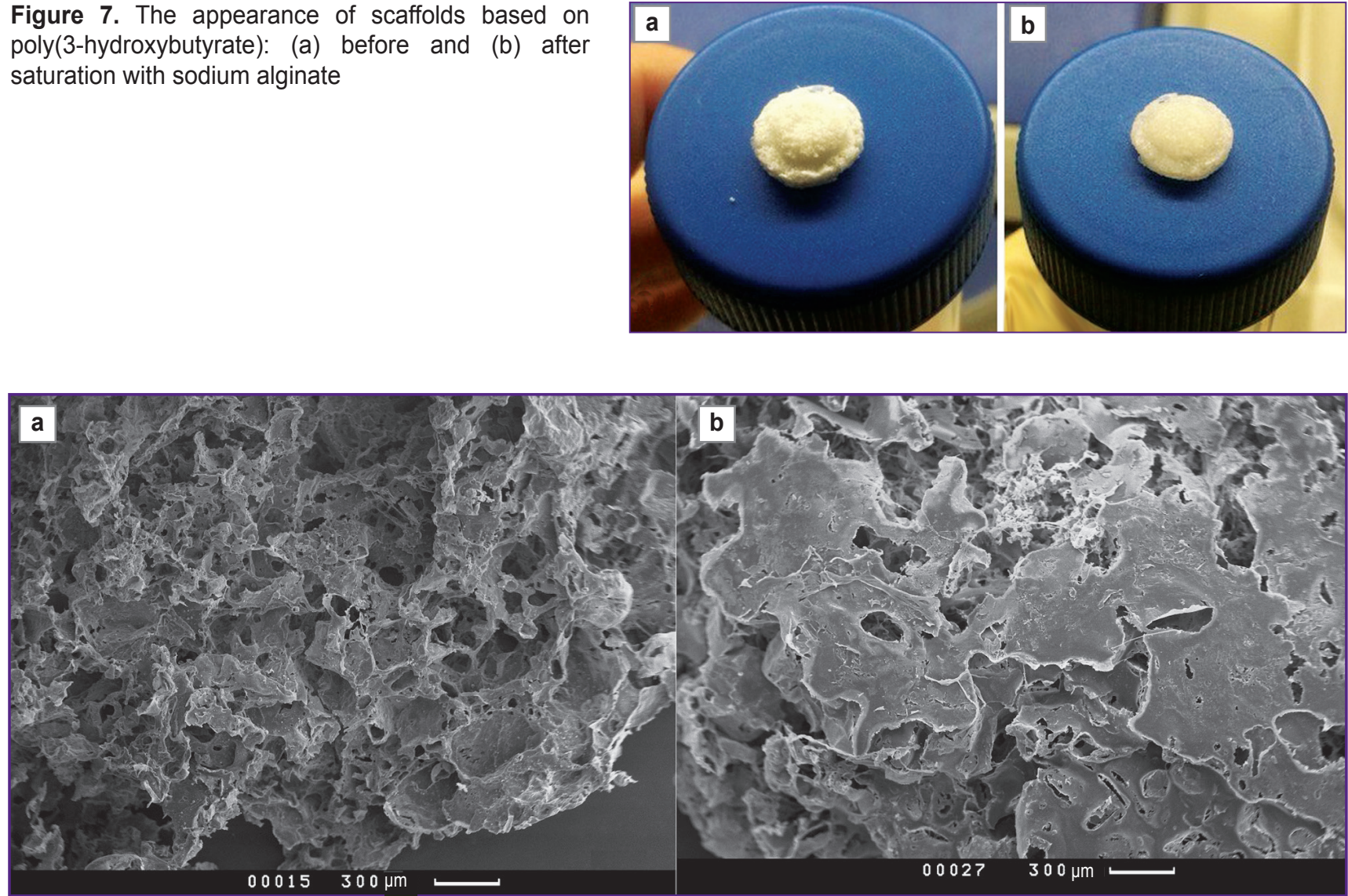

Figure 8. The microstructure of scaffolds based on poly(3-hydroxybutyrate): (a) before and (b) after filling with sodium alginate. Scanning electron microscopy

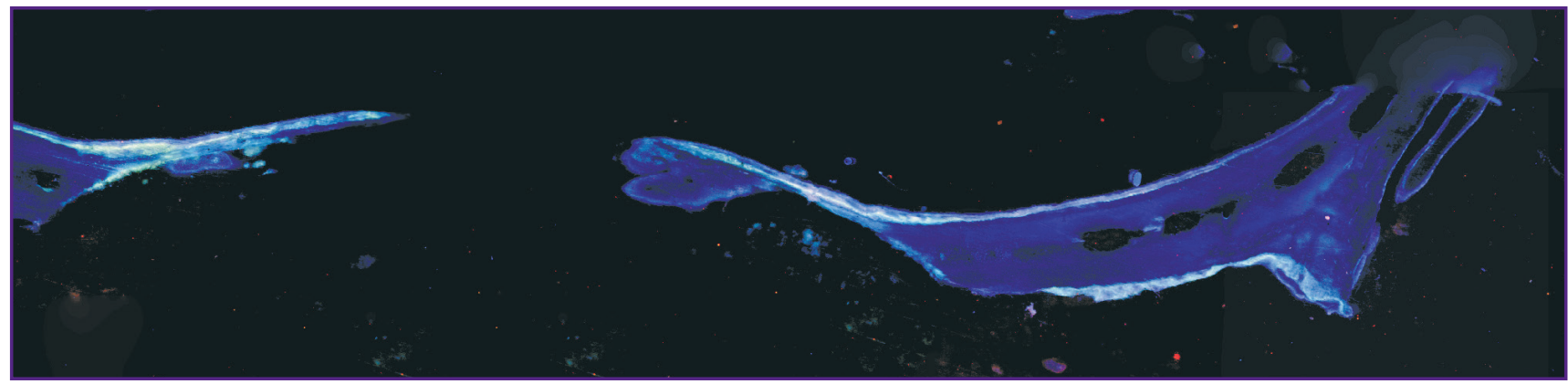

Figure 9. A multi-channel histopantomogram of a histological section of the rats' parietal bones with separate fluorescent marking 28 days after the craniotomy

accumulation areas depending on the observation period (Figure 9).

Conclusion. There has been developed a complex technology for manufacturing hybrid polymer 3D scaffolds of preselected shape and microstructure involving the methods of 3D printing, two-stage leaching and fabrication of hybrid polymer constructions. 3D printing provides the possibility to create molds for manufacturing templates for covering cranial defects no less than $5 \mathrm{~mm}$ in diameter. Two-stage leaching method allows manufacturing scaffolds designed for filling bone defects. The obtained scaffolds present a hybrid construction consisting of various biocompatible polymers - poly(3hydroxybutyrate) and sodium alginate, where alginate is a hydrogel filler of solid, highly porous scaffolds from poly(3-hydroxybutyrate).

The study of histological sections of bone tissue samples using fluorescence microscopy with separate marking by fluorochromes showed that hybrid scaffolds from poly(3-hydroxybutyrate) and sodium alginate 
perform a restrictive function providing conditions for regeneration of flat cranial bones in rats.

The developed hybrid 3D scaffolds do not interfere with normal osteogenesis and provide beneficial conditions for regeneration.

Acknowledgements. The authors express their thanks to Irina V. Arutyunyan for the assistance in carrying out the investigation.

Study Funding. The work was supported by the grant of the Russian Science Foundation (agreement No.15-1510014 dated 01.05.2015).

Conflict of Interests. There is no conflict of interests related to the present study.

\section{References}

1. Jardini A.L., Larosa M.A., Maciel Filho R., Zavaglia C.A., Bernardes L.F., Lambert C.S., Calderoni D.R., Kharmandayan P. Cranial reconstruction: 3D biomodel and custom-built implant created using additive manufacturing. J Craniomaxillofac Surg 2014; 42(8): 1877-1884, https://doi. org/10.1016/j.jcms.2014.07.006.

2. van der Meer W.J., Bos R.R., Vissink A., Visser A. Digital planning of cranial implants. $\mathrm{Br} J$ Oral Maxillofac Surg 2013; 51(5): 450-452, https://doi.org/10.1016/j. bjoms.2012.11.012.

3. Muraev A.A., Dymnikov A.B., Korotkova N.L., Kobets K.K., Ivanov S.Y. Planning technique in maxillofacial plasty. Sovremennye tehnologii v medicine 2013; 5(3): 57-62.

4. Knox G. Surgical bone and cartilage shaping on demand with 3D CAD/CAM. Patent US 8,4838,63 B1. 2013.

5. Jacotti M., Barausse C., Felice P. Posterior atrophic mandible rehabilitation with onlay allograft created with CADCAM procedure: a case report. Implant Dent 2014; 23(1): 2228, https://doi.org/10.1097/ID.0000000000000023.

6. Garagiola U., Grigolato R., Soldo R., Bacchini M., Bassi G., Roncucci R., De Nardi S. Computer-aided design/ computer-aided manufacturing of hydroxyapatite scaffolds for bone reconstruction in jawbone atrophy: a systematic review and case report. Maxillofac Plast Reconstr Surg 2016; 38(1), https://doi.org/10.1186/s40902-015-0048-7.

7. Mangano F., Macchi A., Shibli J.A., Luongo G., lezzi G., Piattelli A., Caprioglio A., Mangano C. Maxillary ridge augmentation with custom-made CAD/CAM scaffolds. A 1-year prospective study on 10 patients. J Oral Implantol 2014; 40(5): 561-569, https://doi.org/10.1563/AAIDJOI-D-12-00122.

8. Kuznetsova D.S., Timashev P.S., Bagratashvili V.N., Zagaynova E.V. Scaffold- and cell system-based bone grafts in tissue engineering (review). Sovremennye tehnologii $v$ medicine 2014; 6(4): 201-212.

9. OPM Receives FDA clearance for $3 D$ printed OsteoFab patient-specific facial device. 2014. URL: https:// www.oxfordpm.com/opm-receives-fda-clearance-3d-printedosteofab-patient-specific-facial-device.

10. Greenstein G., Carpentieri J.R. Utilization of d-PTFE barriers for post-extraction bone regeneration in preparation for dental implants. Compend Contin Educ Dent 2015; 36(7): 465-473.

11. López N.I., Pettinari M.J., Nikel P.I., Méndez B.S. Polyhydroxyalkanoates: much more than biodegradable plastics. In: Advances in applied microbiology.
Elsevier BV; 2015; p. 73-106, https://doi.org/10.1016/ bs.aambs.2015.06.001.

12. Venkatesan J., Bhatnagar I., Manivasagan P., Kang K.H., Kim S.K. Alginate composites for bone tissue engineering: a review. Int J Biol Macromol 2015; 72: 269-281, https://doi.org/10.1016/j.ijbiomac.2014.07.008.

13. Rezwan K., Chen Q.Z., Blaker J.J., Boccaccini A.R. Biodegradable and bioactive porous polymer/inorganic composite scaffolds for bone tissue engineering. Biomaterials 2006; 27(18): 3413-3431, https://doi.org/10.1016/j. biomaterials.2006.01.039.

14. Bonartsev A.P., Zharkova I.I., Yakovlev S.G., Myshkina V.L., Mahina T.K., Voinova V.V., Zernov A.L., Zhuikov V.A., Akoulina E.A., Ivanova E.V., Kuznetsova E.S., Shaitan K.V., Bonartseva G.A. Biosynthesis of poly(3hydroxybutyrate) copolymers by Azotobacter chroococcum 7B: a precursor feeding strategy. Prep Biochem Biotechnol 2016, https://doi.org/10.1080/10826068.2016.1188317. [Epub ahead of print].

15. Bonartseva G.A., Akulina E.A., Myshkina V.L., Voinova V.V., Makhina T.K., Bonartsev A.P. Alginate biosynthesis by bacteria of the genus Azotobacter. Prikladnaya biokhimiya i mikrobiologiya 2017 (in print).

16. Kundu J., Pati F., Hun Jeong Y., Cho D.-W. Biomaterials for biofabrication of 3D tissue scaffolds. In: Biofabrication. Micro- and nano-fabrication, printing, patterning and assemblies. Elsevier BV; 2013; p. 23-46, https://doi. org/10.1016/B978-1-4557-2852-7.00002-0.

17. Gazhva J.V., Bonartsev A.P., Mukhametshin R.F., Zharkova I.I., Andreeva N.V., Makhina T.K., Myshkina V.L., Bespalova A.E., Zernov A.L., Ryabova V.M., Ivanova E.V., Bonartseva G.A., Mironov A.A., Shaitan K.V., Volkov A.V., Muraev A.A., Ivanov S.Y. In vivo and in vitro development and study of osteoplastic material based on hydroxyapatite, poly-3-hydroxybutyrate and sodium alginate composition. Sovremennye tehnologii v medicine 2014; 6(1): 6-13.

18. Ivanov S.Y., Bonartsev A.P., Gazhva Y.V., Zharkova I.I., Mukhametshin R.F., Mahina T.K., Myshkina V.L., Bonartseva G.A., Voinova V.V., Andreeva N.V., Akulina E.A., Kharitonova E.S., Shaitan K.V., Muraev A.A. Development and preclinical studies of insulating membranes based on poly-3-hydroxybutyrate-co-3-hydroxyvalerate for guided bone regeneration. Biomed Khim 2015; 61(6): 717-723, https://doi. org/10.18097/PBMC20156106717.

19. Bai H.Y., Chen G.A., Mao G.H., Song T.R., Wang Y.X. Three step derivation of cartilage like tissue from human embryonic stem cells by 2D-3D sequential culture in vitro and further implantation in vivo on alginate/PLGA scaffolds. J Biomed Mater Res A 2010; 94(2): 539-546, https://doi. org/10.1002/jbm.a.32732.

20. Spicer P.P., Kretlow J.D., Young S., Jansen J.A., Kasper F.K., Mikos A.G. Evaluation of bone regeneration using the rat critical size calvarial defect. Nat Protoc 2012; 7(10): 1918-1929, https://doi.org/10.1038/nprot.2012.113.

21. Pellegrini G., Seol Y.J., Gruber R., Giannobile W.V. Pre-clinical models for oral and periodontal reconstructive therapies. J Dent Res 2009; 88(12): 1065-1076, https://doi. org/10.1177/0022034509349748.

22. Lee C.H., Jin M.U., Jung H.M., Lee J.T., Kwon T.G. Effect of dual treatment with SDF-1 and BMP-2 on ectopic and orthotopic bone formation. PLoS One 2015; 10(3): e0120051, https://doi.org/10.1371/journal.pone.0120051.

23. Vasil'ev A.V. Vliyanie opioida perifericheskogo deystviya 
dalargina na kletochnuyu proliferatsiyu in vitro i reparativnuyu regeneratsiyu kostnoy tkani in vivo. Avtoref. dis. ... kand. med. nauk [The influence of peripherally-acting opioid dalargin on cellular proliferation in vitro and reparative regeneration of bone tissue in vivo. PhD Thesis]. Moscow; 2015.

24. Burr D.B., Allen M.R. Basic and applied bone biology. Academic Press; 2013; 392 p.
25. Handbook of histology methods for bone and cartilage. An Y.H., Martin K.L. (editors). Springer Science + Business Media; 2003; 588 p., https://doi.org/10.1007/978-1-59259417-7.

26. Karageorgiou V., Kaplan D. Porosity of 3D biomaterial scaffolds and osteogenesis. Biomaterials 2005; 26(27): 54745491, https://doi.org/10.1016/j.biomaterials.2005.02.002. 